\title{
COMPARISON BETWEEN LOCATER AND MAGNETIC ATTACHMENT SYSTEMS FOR SINGLE IMPLANT RETAINED MANDIBULAR OVERDENTURE (STRAIN GAUGE ANALYSIS)
}

\author{
Hebatallah Tarek M. Abdallah* and Hanan Mohsen Al-Asad**
}

\begin{abstract}
Objective: the aim of this study was to compare stresses induced in locater and magnetic dome type attachments for single implant retained mandibular overdenture by using strain gauge analysis.

Material and methods: One clear acrylic model was constructed representing completely edentulous lower ridge. A single implant was placed in the midline region of this model and two identical experimental overdentures were constructed. The first overdenture was fitted to single implant through a locater attachment while the second was fitted to implant through a Magnet Dome attachment. Four strain gauges were installed in labial and lingual surfaces and the right \&left sides of single midline implant. A special loading device (universal testing machine) was used to apply standardized static vertical load with a magnitude of $100 \mathrm{~N}$ at the right first molar tooth on the occlusal surface of each experimental overdenture.
\end{abstract}

Results: Comparing the two attachments that were studied, the differences were statistically significant, independent $\mathrm{T}$ test showed significant difference between Locater and Magnetic attachment groups.

Conclusions: Within the limitation of this study, it could be concluded that: magnetic attachment induce less stresses than locater attachment in case of single implant retained mandibular overdenture.

\section{INTRODUCTION}

Dental rehabilitation with traditional removable prostheses in case of atrophic edentulous jaws may create functional problems, because of frequent instability and lack of retention of the prostheses. ${ }^{(1-3)}$
Patients with severely resorbed mandibles often experience problems with their conventional lower dentures. The most probable causes for this is the smaller denture bearing area, unfavorable distribution of occlusal forces resulting in increased rate of bone resorption, loss of denture stability and retention, pain as well as patient discomfort,

\footnotetext{
${ }^{*}$ Lecturer of Prosthodontics, Faculty of Dentistry. Ain Shams University

${ }^{* *}$ Lecturer of Prosthodontics, Faculty of Dentistry, Aden University.
} 
these factors make the use of dental implants and attachments a common practice to overcome the adverse consequences of the conservative treatment. ${ }^{(4,5)}$

Implant supported overdentures generally offer the advantages of improved comfort, support, retention, and stability. In addition, it has been shown that annual bone resorption was more pronounced in patients who wear conventional complete dentures than in those who wear implant supported overdentures. ${ }^{(6,7)}$

The restoration of the edentulous mandible with an overdenture supported and/or retained by two implants placed in the interforaminal region is regarded as the first prosthodontic treatment option. However, in some cases, patients cannot afford treatment with two implants or are not agreeable to accept necessary bone augmentation procedures due to severe mandibular atrophy and economic causes especially poor geriatric patients. ${ }^{(8,9)}$

The new concept is emerging, which uses a single central mandibular implant to retain the mandibular denture. The implant success, prosthetic outcome and patient satisfaction are comparable whether one or two-implants are used for support of mandibular overdentures. In addition to the possible cost savings with a single implant overdenture. ${ }^{(10,11)}$. Regarding the type of attachment systems used in case of single implant overdenture some studies recommended the use of attachment systems with larger dimensions to provide higher retentive forces and that stress breaker ball attachment provided optimal stress distribution as it reflected favorable wear behavior and clinical performance.$^{(12-14)}$
Several stress analysis techniques were used in dental researches to help in the assessment of forces transmitted to oral tissues or those induced by occlusion or prosthetic appliances. Among these techniques, electric resistance strain gauge. ${ }^{(15)}$

There has been little previous research comparing the stresses or strain in the peri-implant bone using single implants retained the mandibular overdentures. Therefore, the aim of this study was to compare stresses induce in locater and magnetic attachment systems for single implant retained mandibular overdenture by using strain gauge analysis.

\section{MATERIALS AND METHODS}

This In-vitro study was conducted on an edentulous clear acrylic mandibular model with single midline implants positioned in the symphasis region.

Edentulous male patient was selected to obtain duplicate of the lower arch for this study from those attending to out-patient clinic, Prosthodontics department, Ain Shams University, The patient exhibited moderate resorbed ridge. Conventional complete denture was constructed for the selected patient.

A final impression was made using conventional method, (zinc oxide eugenol wash impression materials* after border molding with green stick compound $^{* *}$ in open mouth position).Mandibular master cast was obtained after pouring the final impressions with type III dental stone ${ }^{* * *}$. An impression of stone cast was made using silicone impression material ${ }^{* * * *}$. Autopolymerized clear acrylic resin ${ }^{* * * * *}$ with enough amounts was

\footnotetext{
*DPI Impression Paste, the Bombay Burmah Trading Corporation, Mumbai.

** Impression compound type I made in Argentina.

***Stone Plaster, Neelkanth Minechem, Rajasthan, India.

$* * * *$ Speedexcolton A. G, Alsatten, Switzerland

***** Castavaria, Vertex-Dental B.V. The Netherlands
} 
poured into the silicone rubber impression using a mechanical vibrator and a vacuum former machine to avoid porosity and adapt acrylic model to silicone impression material. After the acrylic resin had been set, the clear acrylic model was removed from the cast former and finishing and polishing was done.

Two identical experimental conventional complete mandibular dentures were produced by using duplicating flask technique and autopolymerizing acrylic resin.

Impression of denture was recorded in silicone impression* using a duplicating flask and silicone impression to produce mold Fig (1), after that
Autopolymerizing teeth-colored resin was mixed and added to the tooth indentations space, after the tooth colored resin set, the flask was opened and teeth were removed after that finishing and polishing was done then reinserted into the mold. fig (2)

In this study, one threaded dental implant*, dental milling machine ${ }^{* *}$, surgical stent and a standard surgical drill tools were used to make drill hole in midline of symphyseal region of mandible to locate implant in the mandibular model corresponding to implant fixture dimensions $(3.8 \mathrm{~mm}$ diameter $\times 12$ $\mathrm{mm}$ length) . Self-cure acrylic resin was mixed and applied to fix single implant in its place in midline of edentulous clear acrylic model ${ }^{* * *}$

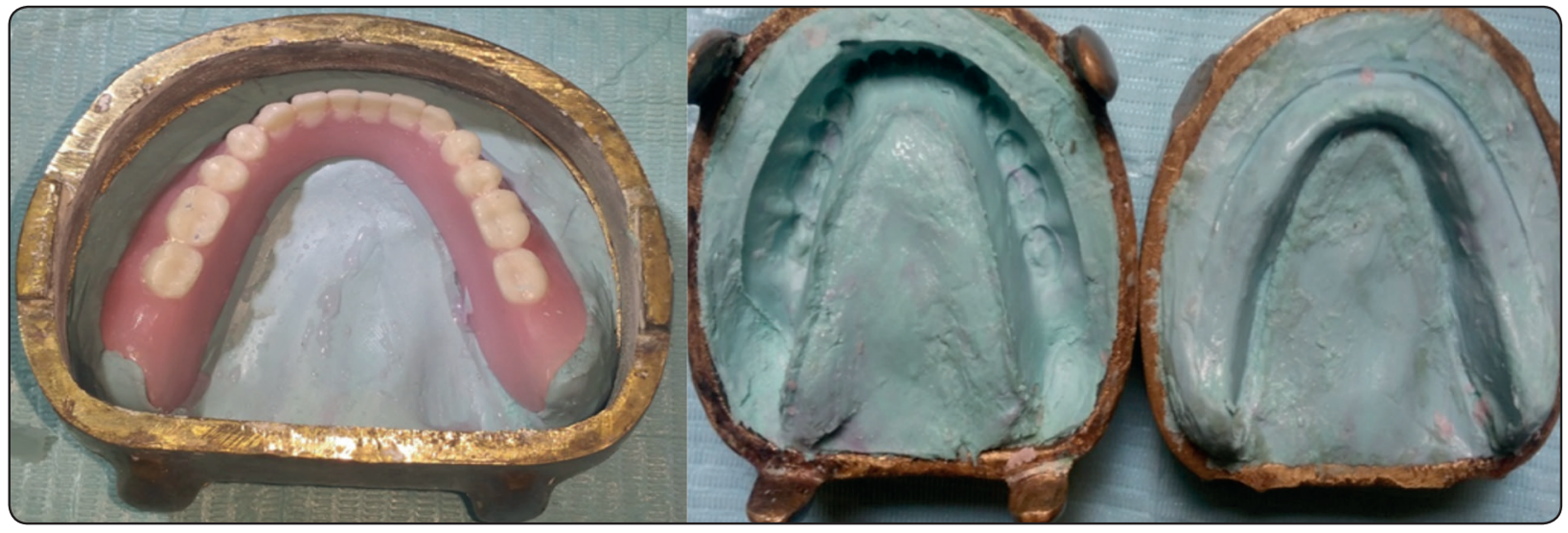

Fig. (1): Impression of denture was recorded in silicone impression

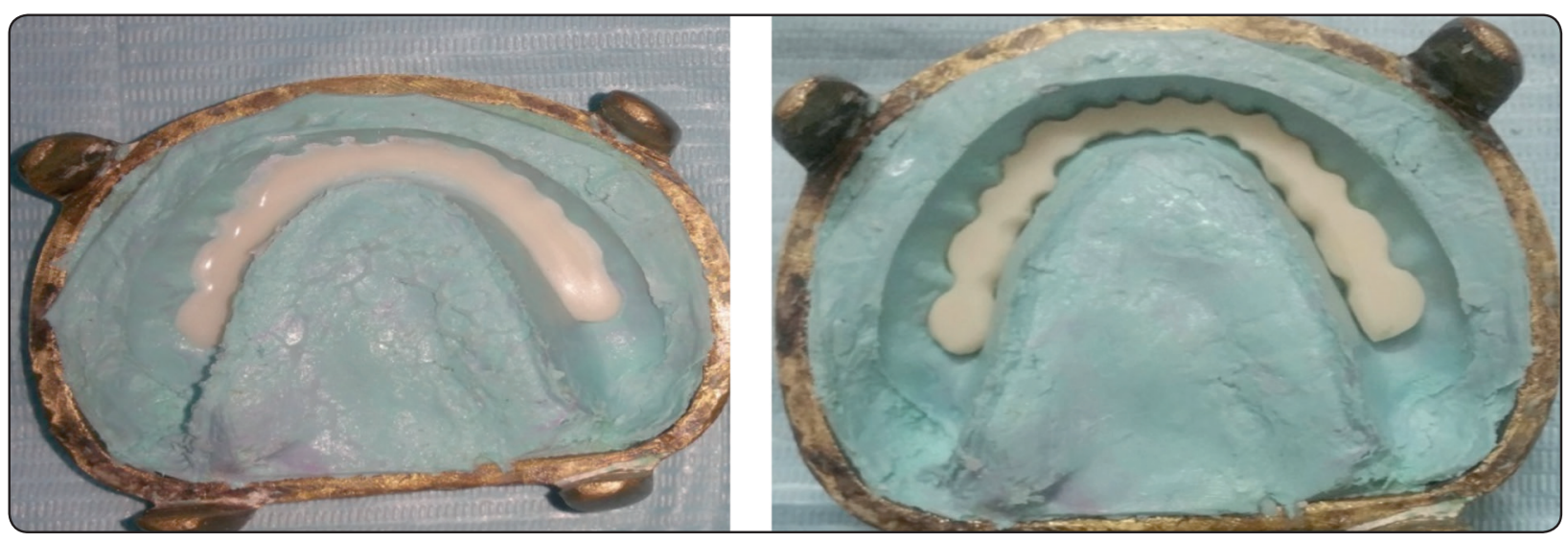

Fig. (2): Autopolymerizing tooth -colored resin a-during setting b-after finishing and polishing

\footnotetext{
* DentiumSuperline - Dentium Inc., Samsung-dong, Gangnam-gu, Seoul, Korea

** Degussa AG, Frankfurt, Germany

*** Repairsin clear, GC Corporation
} 
Two attachment systems* were used in this study Locater attachment : (3.5 diameter and gingival height $2.0 \mathrm{~mm}$ ) and Magnetic attachment (Dome type): (Diameter 3.5, height 2.0) and

For picking up copings in their overdentures, the female parts of attachment systems were picked up into the fitting surface of the experimental overdentures using autopolymerizing acrylic resin.

The first overdenture was fitted to the Locator attachment while the second was fitted to the magnetic Dome type .(Fig .3 a-b).

Simulation of the oral mucosal layer by using Additional -linking gingival mask silicone material ${ }^{*}$ and stone index, a reduced edentulous area was painted by rubber adhesive ${ }^{* *}$. After that, additional-linking gingival mask silicone material with nearly viscoelasticity of the oral mucosa was injected from double-mix cartridge over reduced residual ridge in the clear acrylic model. Then the stone index was repositioned in its previous position after its painting with a separating medium to produce an even thickness of the gingival mask, until setting of gingival mask material.

For installation of the strain gauges, the wires of the strain gauges were oriented vertically in their grooves (labial \& lingual and right \&left side to single midline implant) fixed in a position using an adhesive recommended by the manufacturer. Then the vertical base was prepared $(1 \mathrm{~cm}$ width $-2 \mathrm{~cm}$ height) by using clear autopolymerizing resin then fixed it to the base of clear acrylic model.

Each attachment assembly was screwed to the single midline implant on the model (Fig 4), and overdenture was fitted to its abutment. Then the clear acrylic model was placed on the lower flat metal plate of testing machine. A loading device ${ }^{* * *}$ (universal testing machine) was used to apply standardized static vertical loads with a magnitude of $100 \mathrm{~N}$ at the right first molar tooth on the occlusal surface of each experimental overdentures.(Fig 5) A special load applicator (rod shaped with pointed tip) was used to apply unilateral load in vertical direction for each experimental overdenture. The loading point was unilateral vertically on the right central fosse of first molar and the load was perpendicular to occlusal surface of each overdenture.

Micro strains were recorded of each strain gauges with enough time elapsed between each testing. Once the load was completely applied, the microstrain readings were transferred to microstrain units from four channel strain meter.

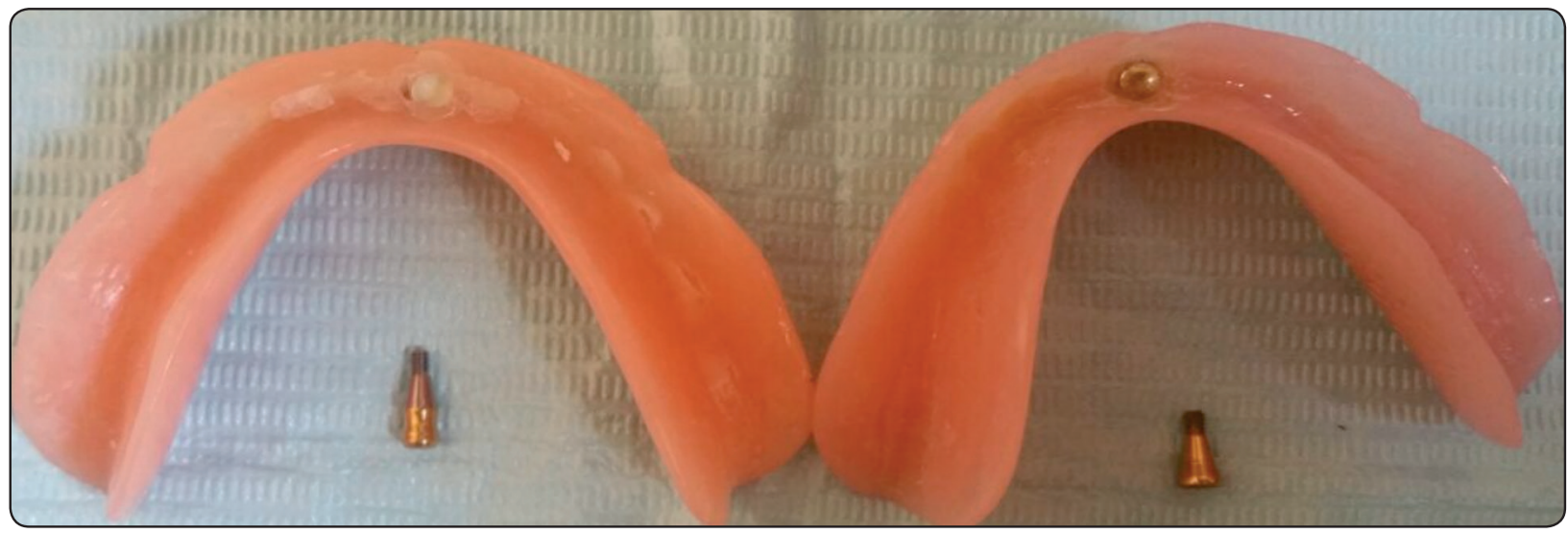

Fig. (3): a) Overdenture with locater attachment b) overdenture with magnetic attachment

\footnotetext{
* Multisil-Mask Soft bredent. Senden .Germany

** Zetaplusa dhesive, Zhermack., Italy

*** Lloyd LR 5K, Hampshire, UK
} 


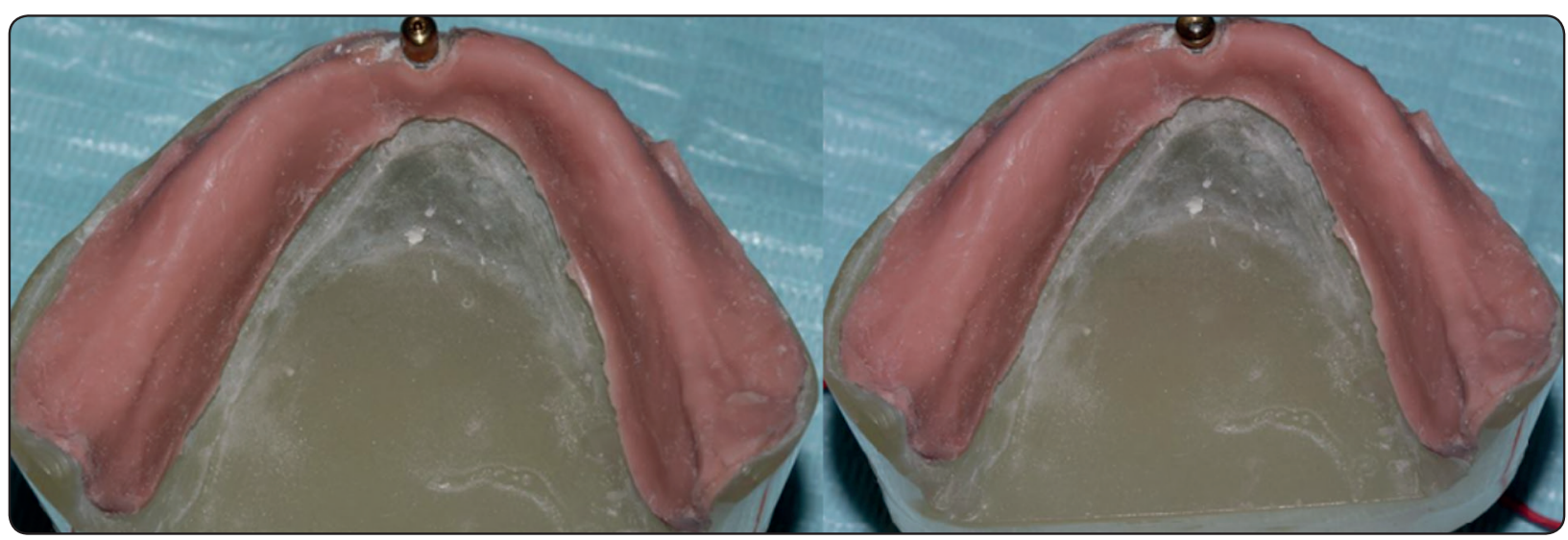

Fig. (4) Head of locater and magnetic dome type attachment screwed in single implant on model.

The same steps were followed with each overdenture after change the supporting abutment and connected it to single midline implant and fitting overdenture to its attachment design.

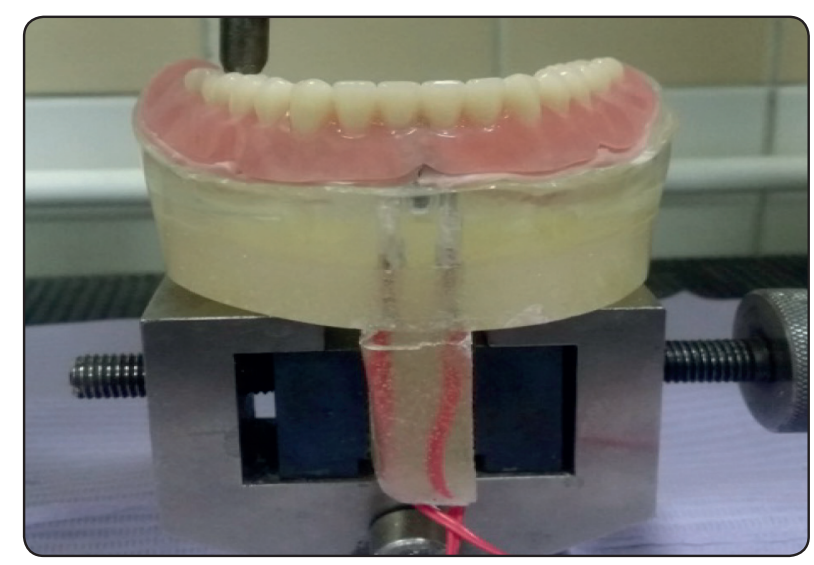

Fig. (5): Unilateral vertical load application on right first molar screwed in single implant on model.

\section{Statistical analysis}

Statistical analysis was performed by Microsoft Office 2010 (Excel) and Statistical Package for Social Science (SPSS) version 20.

Micro-strain data was presented as mean and standard deviation values. The significant level was set at $\mathrm{P} \leq 0.05$. One way ANOVA was used to compare between the four surfaces of single implant for each attachments, if significant differences were detected, the LBE and Simple Mean Value Post hock test was used for comparison between means and independent $\mathrm{t}$ - test was used to compare between the two types of attachments.

\section{RESULTS:}

I-Comparison between microstrains recorded during vertical unilateral posterior loading of locater attachment.

The mean values of recorded microstrains at the left and right sides, lingual and labial surface of the single midline implant with locater abutment when vertical posterior load was applied as shown in the table (I)

Comparing the microstrains recorded during vertical applied load at labial\& lingual surfaces and the right $\&$ left sides of the single midline implant for locater abutment showed that the mean recorded microstrains of labial and lingual surfaces was statistically significant higher than that recorded with right and left side. On the other hand, it revealed statistically significant differences in post hock test between the four surfaces.

II- Comparison between microstrains recorded during vertical unilateral posterior loading of magnetic attachment 
The mean values of recorded microstrains at labial \& lingual surfaces and the left \& right sides of the single midline implant with Magnetic attachment during vertical posterior load was applied are shown in the table (II).

Comparing the mean value of the recorded microstrains showed high statistically significant difference at labial\& lingual surface than right \& left side of single midline implant with magnetic abutment group. On the other hand, it revealed in post hock test all statistically significant differences except for the left vs the right surface.
III--Comparison between means microstrains recorded around single midline implant of two attachments during vertical unilateral posterior load application:

The mean values of the recorded micro strains at the labial \&lingual and right $\&$ left sides of single midline implant when vertical unilateral posterior load application as shown in Table III

Comparing the two attachments that were studied, the results showed that locater abutment group has highest value and there was statistically significant difference between two groups

TABLE (I): Means, standard deviation (SD) values to comparison between four recorded microstrains with vertical unilateral posterior loading of locater abutment design.

\begin{tabular}{|c|c|c|c|c|c|c|}
\hline Vertical load & Labial & Lingual & Left & Right & & P-value \\
\hline Mean \pm SD & $169.50 \pm 1.58$ & $149.00 \pm 2.11$ & $78.00 \pm 2.58$ & $92.00 \pm 2.58$ & \multirow{2}{*}{3827.6} & \multirow{2}{*}{$<0.001$} \\
\hline Range & $165-170$ & $145-150$ & $75-80$ & $90-95$ & & \\
\hline \multicolumn{7}{|c|}{ Post hoc analysis using LSD test } \\
\hline $\begin{array}{c}\text { Labial vs } \\
\text { Lingual }\end{array}$ & Labial vs Left & Labial vs Right & Lingual vs Left & \multicolumn{2}{|c|}{ Lingual vs Right } & $\begin{array}{l}\text { Left vs } \\
\text { Right }\end{array}$ \\
\hline$<0.001$ & $<0.001$ & $<0.001$ & $<0.001$ & \multicolumn{2}{|c|}{$<0.001$} & $<0.001$ \\
\hline
\end{tabular}

TABLE (II): Means, standard (SD) deviation values and results one way ANOV for comparison between recorded microstrains with vertical unilateral posterior loading of Magnetic attachment group

\begin{tabular}{|c|c|c|c|c|c|c|}
\hline Vertical load & Labial & Lingual & Left & Right & F & \multirow{2}{*}{ P-value } \\
\hline Mean \pm SD & $23.50 \pm 2.42$ & $25.00 \pm 0.00$ & $10.50 \pm 1.58$ & $9.50 \pm 1.58$ & $<0.001$ \\
\hline Range & $20-25$ & $25-25$ & $10-15$ & $5-10$ & \multirow{2}{*}{ Left vs } \\
\hline \multicolumn{7}{|c|}{ Post hoc analysis using LSD test } \\
Labial vs
\end{tabular}


Table (III) Comparison of peri-implant strain between two attachments and between sites of strain during vertical unilateral posterior load application:

\begin{tabular}{|c|c|c|c|c|c|}
\hline \multirow{2}{*}{\multicolumn{2}{|c|}{ Strain G Site }} & \multirow{3}{*}{$\begin{array}{c}\text { Locator attachment } \\
\text { No. }=\mathbf{1 0} \\
169.50 \pm 1.58\end{array}$} & \multirow{3}{*}{$\begin{array}{c}\text { Magnet attachment } \\
\text { No. }=\mathbf{1 0} \\
23.50 \pm 2.42\end{array}$} & \multicolumn{2}{|c|}{ Independent t-test } \\
\hline & & & & $\mathbf{t}$ & P-value \\
\hline \multirow{2}{*}{ Labial } & Mean \pm SD & & & \multirow{2}{*}{159.935} & \multirow{2}{*}{$<0.001$} \\
\hline & Range & $165-170$ & $20-25$ & & \\
\hline \multirow{2}{*}{ Lingual } & Mean \pm SD & $149.00 \pm 2.11$ & $25.00 \pm 0.00$ & \multirow{2}{*}{186.000} & \multirow{2}{*}{$<0.001$} \\
\hline & Range & $145-150$ & $25-25$ & & \\
\hline \multirow{2}{*}{ Left } & Mean \pm SD & $78.00 \pm 2.58$ & $10.50 \pm 1.58$ & \multirow{2}{*}{70.501} & \multirow{2}{*}{$<0.001$} \\
\hline & Range & $75-80$ & $10-15$ & & \\
\hline \multirow{2}{*}{ Right } & Mean \pm SD & $92.00 \pm 2.58$ & $9.50 \pm 1.58$ & \multirow{2}{*}{86.168} & \multirow{2}{*}{$<0.001$} \\
\hline & Range & $90-95$ & $5-10$ & & \\
\hline
\end{tabular}

\section{DISCUSSION}

This in- vitro study was conducted to evaluate and compare the generated stresses around single midline implant retaining mandiblular complete overdenture when using locater and magnetic dome type attachments.

The strain gauge technology was used in this study; this technology was used as it is sensitive, stable, accurate and reproducible on the selected sites and can be applied nearly in every situation where strains are to be evaluated, but with a few problems. ${ }^{(16,17)}$ The short comings of the in vitro experiment should be considered. For example, bone density and morphological characteristics may have great variation in different clinical situations, and the patterns of loading in the mouth are far more complex than the application of loads in vitro. Moreover, the simulation of the thickness of the oral mucosa and its properties may change in the mouth, which affects the vertical mobility of the denture. ${ }^{(18)}$

The direct measurement of strains in the dentoalveolar region in humans, result in difficulties in standardization and repeatability of the obtained results, due to the presence of saliva and the possibility of movement of the strain gauges. Also, there are wide variations histological from one patient to another and from different parts within the same mouth ${ }^{(19,20) .}$

Duplicate of a patients edentulous lower ridge, rather than mandibular model used for educational purpose, was used for this study to simulate the real clinical situation and to relate the results of this study to the clinical situation. ${ }^{(21)}$

Duplication of model was done to eliminate the effect of different anatomically incorrect model and to replicate the edentulous patient ridge.

Autopolymerized clear acrylic resin with low shrinkage properties was poured into the rubber base impression using a mechanical vibrator and vacuum machine to avoid bubbles formation. After complete hardening ,the model was removed carefully to get an experimental clear acrylic resin model representing the edentulous mandible with moderate resorbed ridge. 
For standardization as much as possible and for more reliable result one clear acrylic model was used in this study.

Conventional denture was constructed on master cast following the conventional method, then two identical replicas have been made for this denture using silicone impression material for denture duplication. Since this material is sufficiently elastic and can restore to original shape after slight distortion. Also, dimensional changes occurring during setting and handling with this material is comparatively better than that occurring with other materials, Tooth shade-autopolymerizing resin and cold cure pink acrylic were used to ensure the use of same size, shape ,set up of teeth and thickness of dentures base to achieve exact anatomical and mechanical considerations for the test. ${ }^{(22)}$

A lower model was used in this study because of the mandibular conventional complete denture is more problematic than of the maxillary conventional denture due to several factors such as thin mucosal coverage of the edentulous ridge, a reduced support area, the mobility of the floor of the mouth and the movement of the mandible and the tongue which is associated with problem in denture support ,retention and stability. ${ }^{(4)}$ Also the incidence of resorption ridge in the mandible is greater than in the maxilla.

In this study using single midline implant to retain mandibular overdenture was proved to have the same satisfaction and comfort, as several studies were observed in comparison between using single implant and two implants, the results showed same retention, no differences in the post loading of implant, survival ratio, and last but not least lower cost. ${ }^{(23-25)}$

One screw type implant $(3.8 \mathrm{~mm}$ in diameter and $12 \mathrm{~mm}$ length) with two different designs abutments were used to relate the results of this study to the most common clinical situation.
The single implant was placed in the symphyseal region by using a drilling stent, to allow accurately pre-determine the position of and prepare the osteotomy site for the dental implant in both buccolingual and mesio-distal dimensions. The median position of single implant retained overdenture is an excellent host site for an implant in terms of bone quantity and quality.

The overdenture abutment was placed over the single midline implant and fitted precisely to prevent the abutment rotation on the implant. The model was placed and fixed on the table of the milling .For standardization; both attachments were placed on the same model.

Amount of relief was checked by using pressure indicating paste with the female part of attachment fitted to the male abutment so that the clearance is totally passive.

The stone index was used for mucosa simulation, extending to cover labial, buccal and lingual vestibules and the tongue space of the model to assure even thickness and contour of the residual ridge with its resilient covering mucosa, until complete setting of the gingival mask material.

The model used for this study was fabricated to simulate as much as possible the natural condition. The thickness of the tissues covering the ridge affects the amount of denture movement and would be an important related factor in the direction of forces transmitted to the supporting tissue so the surface of the denture bearing area was replaced by 2-mm thick layer of a gingival mask material, which served as artificial mucosa. It was reported that the modulus of elasticity of gingival mask materials to be in the same range with that of the oral mucosa. ${ }^{(26)}$

An adhesive was used between the gingival mask layer and the underlying clear acrylic model, in order to provide stable non movable surface. (27) The strain gauge system was used in this study as it was reported to be a stable and accurate system with 
few problems. The strain gauge assesses strains induced into a loaded structure by converting the change in resistance of an electric wire into strain measurement. ${ }^{(28)}$

The wire used for the strain gauges was insulated by a packing material as a protection from humidity, which was reported to be essential for obtaining reliable recordings ${ }^{(29,30)}$

The first molar was chosen for loading in the posterior region because maximum occlusal forces are often exerted in this area where there is maximum contraction of all elevator muscles. (31) Loading was done with $100 \mathrm{~N}$ as a moderate average level of biting force with implant retained overdenture. ${ }^{(32)}$ Notch on central fossa was done for reproducibility and accommodation of the tip of the loading pin in same location (notch)and to prevent slippage of the $\operatorname{pin}^{(33)}$

Unilateral posterior loading were performed, to simulate the clinical situation as much of the chewing forces are carried unilaterally on the working side during mastication. In this study, unilateral posterior vertical load is used while the anterior loading has been avoided in this study because the anterior forces theoretically are considered destructive to implant retained overdenture.

Micro-strains were recorded at each site of the strain gauge with enough time (fifteen minutes) between each force application to allow complete rebound of the resilient structures before application of the next load.

Our study showed that stresses in the magnetic dome attachment was less than in the locater attachment under unilateral posterior vertical load. This may be attributed to the resiliency of this attachment that permits denture movement in every direction and this movement permits more tissue support for the denture that decrease the stresses transmitted to the implant of this design. Moreover, locater attachment has dual retention so dislodge with high stress than magnetic dome shape attachment.

T. Cheng et al (34) $^{(3)}$ conducted a study on patient satisfaction and masticatory efficiency of mandibular single implant retained overdenture using locators as stud attachment and magnetic (Magfit) attachment. Found that the locator attachment showed slightly better chewing efficiency than Magfit attachment, but there was no statistical significant difference between both the attachments .However, Maeda et al. ${ }^{(35)}$ evaluated the biomechanical rationale for single-implant mandibular over-dentures using magnetic and ball \& socket attachments in an vitro model and found that single implant overdentures had biomechanical properties similar to twoimplants overdentures in terms of lateral forces to the abutment and denture base movements under functional molar loads.

Our study coincide with the results of Nascimento et al. (36) in this study with photoelastic stress analysis it was concluded that the load transmitted to the implant was equally distributed over the single implant retained mandible overdenture when using different attachment systems, with low stresses concentration with Dalla Bona (type of ball attachment) at coronal third and high stresses with locater of single midline implant. Liu et al. ${ }^{(37)}$ in finite element analysis (FEA) under vertical load on the molar region with locater attachment found that a single-implant overdenture tends to rotate over the implant with no detrimental strain concentration was observed in the peri- implant region.

In this study, it was found that a single-implant overdenture has similar biomechanical features to the conventional denture, with primary mucosal support and with the additional advantage of implant retention. Although a single implant is generally less retentive than the two-implants overdenture, patient satisfaction in clinical studies is greatly improved by increasing retention using a single implant, with the additional advantages of lower costs and simpler clinical procedures ${ }^{(25,38)}$ 


\section{CONCLUSIONS}

Within the limitation of this study, it could be concluded that:

Magnetic dome type attachment induce less stresses than locater in case of single implant retained mandibular overdenture

\section{REFERENCES}

1- Mahajan T, Sangur R, Yadav R, Chauhan MS. Prosthetic Management of Edentulous Mandible using Endosseous Implants by Overdentures and Hybrid Dentures: Two Case Reports. J Adv Med Dent Sci Res. 2014;2(3):185-191.

2- Petersen PE, Kandelman D, Arpin S, Ogawa H. Global oral health of older people - Call for public health action. Community Dent Health 2010;27 4 Suppl 2:257-67.

3- Carlsson GE. Clinical morbidity and sequelae of treatment with complete dentures. J Prosthet Dent 1998;79:17-23

4- Stellingsma C, Vissink a, Meijer HJ a, Kuiper C, Raghoebar GM. Implantology and the severely resorbed edentulous mandible. Crit Rev Oral Biol Med. 2004;15(4):240-248.

5- Cheng T, Ma L, Liu XL, et al. Use of a single implant to retain mandibular overdenture: A preliminary clinical trial of 13 cases. J Dent Sci. 2012;7(3):261-266.

6- Van Waas MA. The influence of clinical variables on patients' satisfaction with complete dentures. J Prosthet Dent 1990;63:307-10.

7- Meijer HJ, Batenburg RH RG et al. Mandibular overdentures supported by two Branemark, IMZ or ITI implants: a 5-year prospective study. J Clin Periodontol. 2004;31:522-526.

8- Harder S, Wolfart S, Egert C, Kern M. Three-year clinical outcome of single implant-retained mandibular overdentures-Results of preliminary prospective study. J Dent. 2011;39(10):656-661.

9- Walton JN, Glick N, Macentee MI. A randomized clinical trial comparing patient satisfaction and prosthetic outcomes with mandibular overdentures retained by one or two implants. Int J Prosthodont 2009;22:331-9

10- Cordioli G, Majzoub Z, Castagna S. Mandibular overdentures anchored to single implants: A five-year prospective study. J Prosthet Dent. 1997;78(2):159-165.
11- DeLong R, Douglas WH. Development of an artificial oral environment for the testing of dental restoratives: bi-axial force and movement control. J Dent Res. 1983;62(1):3236.

12- Alsabeeha NH, Atieh M, Swain MV \& Payne AG. Attachment systems for mandibular single-implant overdentures: an in vitro retention force investigation on different designs.Int J Prosth.2010;23(2):160-6

13 Alsabeeha NH, Swain MV \& Payne AGT. Clinical performance and material properties of singleimplant overdenture attachment systems. Int J Prosth. 2011;24(3):247-254.

14- Kono K, Kurihara D, Suzuki Y \& Ohkubo C. In Vitro Assessment of Mandibular Single/Two Implant-Retained Overdentures Using Stress-Breaking Attachments. Implant Dent. 2014;23(4):456-462.

15- Elhemaly MM. The effect of Acrylic Resin Reinforcement on stresses induced on Implant Supported Mandibular Over denture. 2010.thesis for.Ain Shams University

16- Warreth A, Byrne C, Fadel Alkadhimi A, Woods E, Sultan A. Mandibular implant-supported overdentures: attachment systems, and number and locations of implants - Part II. J Ir Dent Assoc. 2015;61(3):144-148.

17-Nikolay M S A, Herrmann FM, Makarov F R.Implant survival in 1- versus 2-implant mandibular overdentures: a systematic review and meta-analysis. 2014:63-72.

18-Bryant SR, Walton JN, MacEntee MI. A 5-year randomized trial to compare 1 or 2 implants for implant overdentures. J Dent Res. 2015;94(1).

19. Tokuhisa M, Matsushita Y \& Koyano K. In vitro study of a mandibular implant overdenture retained with ball, magnet, or bar attachments: comparison of load transfer and denture stability. Int J Prosth .2003. 16(2):128-134.

20. Castilho AA, Kojima AN \& Pereira SMB. In vitro evaluation of the precision of working casts for implantsupported restoration with multiple abutments. J Appl Oral Sci. 2007;15(3).

21. Elhemaly MM. The effect of Acrylic Resin Reinforcement on stresses induced on Implant Supported Mandibular Over denture. 2010.Thesis MD Ain Shams University

22. RajapurA.Duplication of complete dentures using autopolymerizing acrylic resin: a review of techniques, 2011.2(1). Int J prosdent 
23. Żmudzki J, Chladek G \& Kasperski J. Silicone attachment for avoidance of bone tissue overloading in single implantretained denture. Int Sci J. 2011;51(2):107-115.

24. Srinivasan M, Makarov NA \& Herrmann FR. Implant survival in 1- versus 2-implant mandibular overdentures: a systematic review and meta-analysis. 2014:63-72.

25. Mundt T, Passia N, Att W, Heydecke G, Freitag-Wolf S, Luthardt RG, Kappel S, Konstantinidis IK, Stiesch M, Wolfart S, \& Kern M. Pain and discomfort following immediate and delayed loading by overdentures in the single mandibular implant study .Clin Oral Investig. 2017; 21(2):635-642.

26. Hussein LA. 3D finite element analysis of the influence of different soft lining materials with variable thicknesses on stress transmitted to underlying mucosa. Int $\mathbf{J}$ Adv Res (. 2014;2(12):896-905.

27. Sulong MZ, Setchell DJ. Properties of the tray adhesive of an addition polymerizing silicone to impression tray materials. J Prosthet Dent. 1991;66(6):743-747.

28 Rodrigues M, Luthi L, Takahashi J, Nobilo M\& Henriques G. Strain gauges's analysis on implant-retained prosthesis' cast accuracy. Indian J Dent Res. 2014;25(5):635.

29. Winkler S. Essential of complete denture prosthodentics. 2 Ed.india A.I.T.B.S. 2009

30. Srinath LS, Raghavon MR, Lingalah K GG \& RK. Experimental stress analysis. In: McGraw-Hill, ed. 2nd ed. Co., London,; 1984:245.

31. Celik G, Uludag B. Photoelastic stress analysis of various retention mechanisms on 3-implant-retained mandibular overdentures. J Prosthet Dent. 2007;97(4):229-235.
32. Mericske-Stern R, Hofmann J, Wedig A \& Geering AH. In vivo measurements of maximal occlusal force and minimal pressure threshold on overdentures supported by implants or natural roots: a comparative study, Part 1. Int J Oral Maxillofac Implants. 1993;8(6):641-649.

33- ELsyad MA, Errabti HMZ \& Mustafa A Z. Mandibular Denture Base Deformation with Locator and Ball Attachments of Implant-Retained Overdentures, J pros : J Am Col Pros, 2015:1-9

34-. Cheng T, Sun G, Huo J, He X, Wang Y \& Ren YF. Patient satisfaction and masticatory efficiency of single implantretained mandibular overdentures using the stud and magnetic attachments. J Dent. 2012;40(11):1018-1023.

35- Maeda Y, Horisaka M, Yagi K. Biomechanical rationale for a single implant-retained mandibular overdenture: an in vitro study. Clin Oral Implants Res. 2008;19(3):271-275.

36- Nascimento JFM, Aguiar-Júnior FA, Nogueira TE, Rodrigues RCS, Leles CR. Photoelastic Stress Distribution Produced by Different Retention Systems for a Single-Implant Mandibular Overdenture. J Prosthodont. 2015;24(7):538-542.

37- Liu J, Pan S, Dong J, Mo Z, Fan Y, Feng H. Influence of implant number on the biomechanical behaviour of mandibular implant-retained/supported overdentures: A three-dimensional finite element analysis. J Dent. 2013;41(3):241-249.

38-Patil PG* SL and TM. Single Versus Two Dental Implant Retained Mandibular Overdenture: Study Protocol for a Randomized Controlled Trial. Dent Implant Dentures;Open Access. 2016;1(1):1-5. 